\title{
A ABORDAGEM ERGOLÓGICA E O MUNDO DO TRABALHO DOS COMUNICADORES
}

\author{
THE PERSPECTIVE OF ERGOLOGY AND THE COMMUNICATOR'S THE WORLD OF WORK
}

Roseli Figaro ${ }^{1}$

Resumo Com base nos resultados da pesquisa "As mudanças no mundo do trabalho nas empresas de comunicação" da autora, discutem-se, neste artigo, aspectos relativos aos valores e às escolhas inerentes à atividade de trabalho dos comunicadores. Na primeira parte, trata-se da centralidade do trabalho e da comunicação na sociedade contemporânea. Toma-se como referencial teórico o conceito de atividade humana de trabalho, a partir do qual se estabelece a aproximação entre a ontologia do ser social de Marx e a abordagem ergológica. Na segunda parte, discute-se a contradição que se apresenta na prática profissional do comunicador em relação ao direito à informação. Essa contradição, entre prática profissional e direito à informação, foi apontada como um dos resultados da investigação. A pesquisa analisou os dados obtidos por meio de entrevistas com uma amostra de comunicadores, funcionários em duas empresas do ramo da comunicação. A discussão permite evidenciar os valores profissionais e as injunções do sistema de produção nos debates e conflitos que o jornalista enfrenta consigo mesmo ao fazer suas escolhas para realizar o trabalho. Esses embates são enfrentados pelo profissional no contexto do sistema de grandes conglomerados de empresas de comunicação e fusão de mídias. Ao final, faz-se um balanço geral dos resultados.

Palavras-chave comunicação; mundo do trabalho; atividade humana de trabalho; direito à informação.
Abstract On the basis of the results presented on the research project entitled "Changes of the world of work on the communication companies", this article discusses characteristics of the values and choices inherent to the work activity of professionals of communication. The first part discusses the centrality of the work and of the communication on the contemporaneous society. Here the theoretical reference is the concept of human activity of work, from which an approximation between the ontology of the social being of Marx and the ergological approach is established. On the second part of the article we discuss the contradictions, evinced by the research project, that are present on the professional practice of the communication in relation to the right to information. The research project presents the analysis of data obtained by means of interviews with professionals of communication, employees of two different communication companies. The discussion allows us to evince the professional values and the injunctions of the system of production on the selfdebates and selfconflicts that the workers faces when making their professional choices, in the context of the system of the big conglomerates of communication and media fusion companies. As a conclusion a balance of the indicators resulted from the research is presented.

Keywords communication; world of work; human work activity; right to information. 
A análise das situações de trabalho, objeto da ergologia, é um desafio para os pesquisadores da área das ciências da comunicação. Isso se dá devido a dois motivos. O primeiro diz respeito à dificuldade de se conseguir apoio e permissão para a observação da atividade de trabalho dos profissionais in loco. As empresas de comunicação são conglomerados que gozam de muito prestígio e poder. Não há uma cultura da pesquisa nas empresas sem o compromisso de reiterar a priori os valores da própria empresa. O segundo motivo relaciona-se ao tipo de atividade. Os comunicadores têm um trabalho cujo material são os discursos e linguagens (verbal e não verbal) com as quais se cria o produto cultural (Morin, 1997). Os profissionais da área têm uma cultura de que são eles os observadores da sociedade, são eles a colherem os relatos, a filmarem e a registrarem os movimentos e a criarem mensagens para um 'outro' sempre percebido e referido como público consumidor.

A par dessas dificuldades, inerentes ao fazer profissional, existem outras, que dizem respeito, de forma geral, ao objeto de estudo: o trabalho e as relações de comunicação no trabalho, visto que é difícil para aquele que trabalha falar de suas próprias atividades sem remeter-se à prescrição da tarefa.

Tendo em vista tais dificuldades, este artigo discute, com base nos resultados da pesquisa "As mudanças no mundo do trabalho nas empresas de comunicação", 2 alguns aspectos teóricos demandados pela aproximação de comunicação e trabalho, sobretudo aqueles advindos dos conflitos entre as rotinas produtivas e o direito à informação.

Na primeira parte, a discussão se dá tendo como pressuposto a centralidade do trabalho e da comunicação na sociedade contemporânea, o que permite formular o binômio comunicação e trabalho. Toma-se como referencial teórico o conceito de atividade humana de trabalho, conformado por duas abordagens: a do materialismo histórico, que relaciona a produção material à produção do ser social (uma ontologia do ser social), e a ergológica, que destaca a atividade humana como sempre inédita e renormalizadora das situações de trabalho.

Na segunda parte, ambas as abordagens são mobilizadas para discutir a relação do profissional com a informação produzida (relatada/recortada/enunciada) por ele e o direito à informação. Evidenciam-se os valores e as injunções do sistema de produção nas "dramáticas do uso de si por si mesmo e de si pelo outro" no sistema dos grandes conglomerados de comunicação e da fusão de mídias, da precarização dos vínculos de trabalho e do comunicador multiplataformas. Nas considerações finais, faz-se uma síntese dos resultados da pesquisa.

\section{Ergologia e a atividade de comunicação e de trabalho}

A abordagem ergológica propõe-se como uma epistemologia, uma reflexão que fricciona o 'saber da experiência' no 'saber instituído' da ciência, dos 
conceitos (Schwartz e Durrive, 2007). A ergologia tem a atividade humana de trabalho como aquela responsável pela dialética que põe em movimento o homem e seu meio, construindo valores éticos e materiais, fazendo, assim, concretamente a história.

A atividade industriosa, por definição, é contraditória e complexa, sempre inédita. A ergologia destaca, na atividade de trabalho, o encontro da norma - prescrição, conhecimento acumulado - com a sua renormalização, visto que a norma é atualizada pelo inédito da atividade no processo de sua realização (Schwartz, 1997). Dessa forma, nunca há o acabado, o definitivo, o modelo intransponível, pois é da natureza humana o fazer sempre em relação às condições concretas desse fazer.

Essa formulação sobre a atividade humana de trabalho interessa particularmente ao campo científico da comunicação. Isso porque também se entende o conceito de comunicação como constitutivo do humano; não se restringindo às demandas e às produções vinculadas aos aspectos técnicoprofissionais dos meios de comunicação, sejam eles aparatos analógicos ou digitais. Por exemplo: restringir o objeto de estudo da área aos meios de comunicação atende pontualmente a questões relativas a determinadas perguntas de pesquisa. Mas não alcança outros níveis de problema, como as questões que dizem respeito às relações de comunicação na sociedade, entre os diferentes grupos, identidades e classes ou aos processos produtivos, às rotinas profissionais, ou ainda ao processo de diferenciação, seleção e combinação de signos inerente à construção de sentidos.

Estudar a comunicação como aspecto da atividade humana de trabalho dá ao conceito um caráter ontológico, no sentido da ontologia do ser social que Marx discute nos Manuscritos econômicos filosóficos, de 1844, conforme comentam Costa e Vasconcelos:

Isso faz com que na ontologia marxiana consciência e realidade objetiva sejam compreendidas como dois momentos com o mesmo estatuto ontológico, ou seja, a consciência não é um simples epifenômeno da realidade objetiva. É interessante destacar que a relação fundado-fundante está posta em termos ontológicos, noutras esferas como a política ou a educação, por exemplo. Dependendo de cada caso concreto pode ocorrer uma inversão quanto à importância da subjetividade ou da objetividade - sem esquecer que estas são categorias reflexivas que só na abstração podem ser desmembradas. Daí a extrema distância da perspectiva ontológica marxiana que possui como fundamento a unidade indissolúvel entre subjetividade e objetividade, presente na atividade matriz da sociabilidade, o trabalho (Costa e Vasconcelos, 2008, p. 6, grifos nossos).

Dito em outras palavras, entre ser e objeto, a existência de ambos é dada pela atividade humana de trabalho, derivada da relação social, da sociabilidade 
que comportam as relações de comunicação. Assim, analisar a atividade de trabalho e de comunicação, no contexto social e histórico em que elas se realizam, é articular o micro e o macrossocial, é entender a materialidade do trabalho na constituição do ser que trabalha e da sociedade em que ele se insere.

Essa afirmação implica reconhecer que comunicação e trabalho são fundamentos da sociabilidade humana. A comunicação é uma conquista da espécie, efetivada pela condição do homem de sobrepor-se, por meio de sua atividade de trabalho, às condições da natureza. A comunicação por meio da linguagem humana está ligada, desde a origem, à atividade produtiva, à “comunicação material dos homens" (Leontiev, 1976). Schwartz afirma que

(...) as relações entre linguagem e trabalho são imemoriais. Talvez não exatamente imemoriais, pois existe, de algum modo, uma defasagem. Podemos pensar que houve um 'fazer' na humanidade, um fazer industrioso, um fabricar que antecedeu a linguagem em, talvez, um milhão de anos. Não se sabe muito bem a partir de quando essa linguagem acompanhou todas as outras atividades e, evidentemente, a atividade do fazer (Schwartz, 2007b, p.133).

A atividade para a sobrevivência, no enfrentamento das "infidelidades do meio", requer a comunicação entre os seres para que haja cooperação e, por conseguinte, superação das dificuldades.

Dessa forma, a linguagem não é uma ferramenta de comunicação entre os homens, ela é constitutiva do homem e uma forma da consciência e do pensamento. Ela acompanha, comenta, projeta a atividade de trabalho e, como afirmam Bakthin/Voloschinov (1988), é uma arena das lutas sociais. Ela reflete e refrata as menores mudanças sociais. A comunicação tem na linguagem verbal, na palavra, a síntese da arena das lutas sociais, porque se forja na dialética entre o estabelecido e o vir a ser. A palavra é sensível às mudanças sociais porque é parte da atividade humana de trabalho. E é a atividade de comunicação e de trabalho o material objetivo, com o qual se fabrica a realidade humana. A palavra é o que mais se aproxima e acompanha a atividade de trabalho. É por isso que Schwartz (2007b) fala em "atividade linguageira".

Essa apropriação do conceito de atividade de trabalho distancia-se de uma metafísica idealista, a qual projeta na força imanente do cosmos a explicação para a existência e o fazer humanos. Forçosamente, tal relação com a ontologia do ser social opõe-se à disrupção entre atividade humana e história; entre atividade humana e condições materiais e culturais da existência da sociedade. O 'inédito' do trabalho, a sua 'impossível' antecipação articula-se dialeticamente com o conhecido, o estabelecido, o 'prescrito da norma' e das regras e forças estabelecidas pela hegemonia do poder dominante. O inédito e o impossível (Schwartz, 2007a), por outro lado, não 
são aspectos de forças ocultas, oriundas de um ser superior. O inédito e o impossível da atividade humana são aspectos próprios à atividade, ao embate do homem com seus recursos psicofísicos e com o seu meio, na construção de si e da sociedade humana. Nas palavras de Schwartz (2007b, p. 96, grifo do autor): “A variabilidade do meio técnico torna impossível a estandardização total. Além disso, o homem aumenta essa variabilidade porque se submeter inteiramente às normas seria para ele invivivel".

Devido a essa perspectiva é que se articula a ergologia com a ontologia do ser social ${ }^{3}$ para que a atividade de comunicação e de trabalho possa revelar a norma, a prescrição como o conjunto dos "conhecimentos instituídos" (Schwartz, 1997), historicamente determinados e dialeticamente renormalizados pela atividade inédita de trabalho. Essa articulação possibilita ver em movimento, sempre transformador, a atividade de trabalho e, portanto, a realidade social. Veem-se em movimento as forças produtivas e as relações de produção. Compreende-se como a atividade de trabalho e de comunicação, fundamentos da subjetividade e da sociabilidade, são fontes da criatividade, da inovação da produção material, das relações de produção e de poder político, bem como da transformação da sociedade.

A análise das situações de trabalho, na perspectiva ergológica, articulada à ontologia do ser social, possibilita que se apure a observação e a compreensão dessas situações a partir do sujeito que trabalha, das redes de relações que permitem que se trabalhe e da formação dos conjuntos de coletivos (trabalhar é sempre trabalhar com o outro). Sem, no entanto, deixar de problematizar o sistema socioeconômico instituído, a exploração econômica do trabalho e as diferenças entre os interesses de classe. Jacques Duraffourg (2007, 62-63), tratando do tema, afirma: “Interessar-se pelo trabalho é se interessar por esta dialética fundamental entre o singular e o geral. Não assumir todas as conseqüências desta dialética conduz a um verdadeiro massacre $(. .$.$) ". Entende-se desse enunciado que o "geral" não se restringe à$ descrição das condições de trabalho stricto sensu, pois tais condições estão inseridas na história do sistema de relações de produção.

$\mathrm{Na}$ articulação entre comunicação e trabalho, na perspectiva da ergologia e da ontologia do ser social, consideram-se as profundas mudanças ocorridas no mundo do trabalho a partir da incorporação das tecnologias de informação e de comunicação, bem como da expansão mundial do capitalismo. Mudanças que incidem no particular, no imediato, no invisível do trabalho, pois atuam sobre as formas de perceber, de se relacionar, de produzir cultura (no sentido antropológico)

Por isso, destaca-se, mais uma vez, a relevância da comunicação para a análise das situações de trabalho. Sem a comunicação não é possível a atividade de trabalho. A importância da comunicação é sobrelevada devido às possibilidades que o homem cria com o desenvolvimento das novas tecnologias 
digitais. Elas ampliam em muito a capacidade de relação, de articulação, de contato dos homens em atividade. Os dispositivos informacionais, como artefatos (Folcher e Rabardel, 1998) produzidos pela atividade humana, concretizam-se, como instrumentos, pela competência do homem em utilizá-los. Esses artefatos tecnológicos em uso na atividade de trabalho atuam na sensibilidade, na percepção, e requerem a formulação de novas estratégias para acioná-los no trabalho. Em concomitância, é pelo inédito da atividade que a técnica e a tecnologia 'funcionam' e se renovam. Ao mesmo tempo, esse 'inédito' da atividade, que cria novos usos e estratégias, está conformado historicamente por um determinado sistema socioeconômico e político. Aí está mais um embate de normas (vinculando o micro ao macrossocial), abrindo as possibilidades de transformação das relações sociais.

No caso do comunicador, os signos verbais e não verbais são o 'material' com que se trabalha. A atividade do comunicador depende das relações de comunicação no mundo do trabalho e de suas competências em lidar com as linguagens (sobretudo a linguagem verbal), material que 'manuseia' objetivando a produção de determinados sentidos.

Tendo em vista os aspectos teóricos discutidos, tratar-se-á, na sequência, de apresentar pontos relevantes que conformam as normas e as prescrições das rotinas profissionais, tendo em conta os relatos sobre experiências no trabalho de comunicadores entrevistados na pesquisa "As mudanças no mundo do trabalho nas empresas de comunicação".

\section{A atividade de comunicação e de trabalho dos comunicadores}

\section{Cenário}

A concentração internacional do setor da comunicação, segundo Faustino (2004), expressa-se na reunião dos meios de comunicação em cinco ou seis grupos empresariais, cada vez mais poderosos, que concentram $50 \%$ das receitas publicitárias e das grandes tiragens de jornais e revistas em todo o mundo.

As observações de Faustino manifestam-se também no Brasil, sobretudo, no que diz respeito à ancoragem nas tecnologias e nas práticas de gestão e marketing. A pesquisa citada anteriormente confirmou o que já indicava o estudo da Unesco, publicado em 2000, Rapport mondial sur la culture, que trata da concentração das empresas de comunicação e, em decorrência, da falta de pluralidade de pontos de vista nos discursos nas mídias. No Brasil, os dados da pesquisa "Perfil da economia da cultura", realizada pelo IBGE, 2003-2005, também apontam a relevância e especificidade do setor da economia da cultura, bem como a tendência de concentração. 
Nesse sentido, o cenário de rearranjo das empresas de comunicação é um índice da concentração desse mercado e das disputas que ocorrem entre as grandes empresas do setor no Brasil. Elas são empresas familiares que profissionalizaram suas direções e contam com participação de capital externo (30\%), conforme permite a legislação brasileira. ${ }^{4}$ Tais aspectos devem ser levados em consideração quando se trata de analisar o mundo do trabalho do profissional de comunicação. Ao assim proceder, opera-se o que já indicou Duraffourg (2007), ao ressaltar a importância da articulação do singular e do geral, e esclarece-se que o inédito da atividade de trabalho sempre está conformado pela história, pelas condições objetivas do desenvolvimento psicofísico e socioeconômico.

A atividade de trabalho no setor da comunicação goza de certo status social. O setor é visto pela coletividade como aquele que propicia ao profissional destaque e diferenciação em relação a outros trabalhadores e exige, por isso, determinadas características e habilidades que fazem desse profissional uma pessoa autorizada a transitar por diferentes setores, classes, grupos e, daí, a construir discursos e representações sobre esses grupos e contextos. E, em consequência, construir sobre si próprio uma representação social que lhe dá o consentimento pressuposto de que desempenha seu trabalho resguardando o interesse público e os valores éticos da cidadania. Enfim, esse conjunto positivado socialmente passa a compor certa deontologia das rotinas profissionais, seja ela do jornalista - objetividade, verdade -, seja do publicitário - informação confiável -, seja do relações públicas mediação para o diálogo entre diferentes públicos.

Esses conjuntos de valores compõem os 'saberes instituídos' da atividade de trabalho dos comunicadores. Fazem parte das normas, dos discursos que 'dizem' o que é essa prática profissional. São também enunciados transmitidos e discutidos na formação universitária, reafirmando-lhes o peso de norma, prescrição.

Mas como efetivá-los na atividade de trabalho, como reafirmá-los na prática cotidiana no cenário descrito de oligopolização das empresas, de supremacia da receita publicitária, em detrimento da pluralidade de informações e de pontos de vista?

\section{As dramáticas do uso de si na atividade dos comunicadores}

É na atividade de trabalho que esse confronto se dá de maneira a exigir do profissional maior engajamento de si no trabalho para renormalizar a norma no sentido de reafirmar e renovar a deontologia que comporta os valores da cidadania (valores imensuráveis, para Schwartz), buscando as brechas para enfrentar os desacordos, as pressões etc., ou renormalizar a norma 
para atender à demanda da premência dos tempos, das opiniões, das injunções políticas e, sobretudo, da receita publicitária (valores mensuráveis, para Schwartz).

Assim, é preciso chamar a atenção para o mundo do trabalho dos comunicadores, considerando as "dramáticas do uso de si por si mesmo e pelo outro", ou seja, como os profissionais enfrentam os desafios cotidianos e a partir de quais valores fazem suas escolhas para se porem em atividade de trabalho, visto que lhes são requisitadas competências e habilidades para produzirem - nas condições de um novo ambiente tecnológico (multi e transmidiático), em curto tempo, sob pressões do contexto econômico - um produto cultural acabado.

Schwartz (1997) chama de "dramáticas do uso de si por si mesmo e por outro" o uso que fazemos de nós mesmos e o uso que o 'outro' faz de nós para a execução do trabalho. Entende-se por 'dramática' o movimento entre norma prescrita, infidelidade do meio, renormalização e atividade singular. A dramática é a contradição inerente a 'toda' atividade de trabalho, própria da vida, e é potencializada pelo conflito entre as diferenças socioeconômicas, pela apropriação mercantil do trabalho, pela desvalorização do trabalho. Tais condições estão bastante recrudescidas no ambiente profissional dos meios de comunicação.

É na atividade de trabalho que estão implicados, no caso do mundo do trabalho dos comunicadores, os valores éticos que permitem fazer escolhas, adotar critérios, estabelecer procedimentos e rotinas produtivas que se tornam regras, manuais, técnicas. O senso crítico permanente (sempre voltado para o bem comum) deveria orientar a atividade do "corpo-si" na permanente tomada de decisão do que deve ou não ser reportado, publicizado.

A fala de um profissional conhecido como Caco Barcellos ilustra a dimensão dos embates do prescrito com o real da situação de trabalho e como os valores conformam a atividade do sujeito, "corpo-si" do trabalho.

E é barato você fazer denúncia baseada em uma declaração. Não tem nenhuma prova. Hoje, estão fazendo denúncia ao vivo. A Internet, o rádio e a televisão fazem isso. Qual o critério de avaliação que temos? É verdade ou não o que estamos ouvindo? Posso falar o que eu quiser. Se sou jornalista, tenho obrigação de provar que estou falando a verdade. Se confessar um crime bárbaro, você tem obrigação de provar que a minha confissão é verdadeira. Isso é jornalismo com responsabilidade. O contrário é jornalismo denuncista, leviano. Mas é assim que está sendo feito. E é muito mais barato, concorda? (Entrevista à pesquisadora em 2007).

A gestão de si por si mesmo e de si pelos outros, subentendida na fala de Barcellos, marca como esse cenário macrossocial de profissionalização das empresas de comunicação, tendo a informação como um negócio como 
outro qualquer, faz da atividade de trabalho um embate problemático das normas e dos valores, questionando a finalidade do resultado apresentado.

Para corroborar a fala de Barcellos, destaca-se o artigo 19 da Declaração Universal dos Direitos Humanos, o qual estabelece a informação como um dos direitos humanos fundamentais. A partir desse direito, formula-se uma série de discussões sobre o papel dos meios de comunicação na sociedade. Problematiza-se a relação da mídia com a sociedade civil, com o poder político e com o poder econômico, dando origem à teoria da mídia como 'quarto poder' 5 e da responsabilidade social do jornalismo, 6 bem como aos princípios deontológicos e aos valores éticos dos profissionais da área. Válidos todos eles a depender sempre do primeiro fundamento, ou seja, o do direito à informação. Em 1983, a Unesco fez uma declaração sobre os meios de comunicação que "evoca a noção de uma responsabilidade social inerente a este setor ao preconizar que, no jornalismo, 'a informação é entendida como um bem social e não como um simples produto (...)'” (Morais, 2007, p. 112).

Como se vê, o profissional da comunicação em sua atividade de trabalho é confrontado a todo o momento com valores que o questionam como profissional e como cidadão.

Esse tema é tão relevante para a atividade de trabalho do comunicador que, ao serem indagados sobre a especificidade do trabalho que exercem e os fatores externos que mais a influencia, os comunicadores das duas empresas que permitiram a pesquisa, uma agência publicitária e uma empresa editorial, responderam ser "a receita publicitária o fator preponderante a influenciar suas atividades". Essa percepção para o negócio da publicidade, no caso da agência, é naturalizada à medida que é a sua matéria de trabalho; mas, para os comunicadores da empresa editorial, a receita publicitária não é o produto final de seu trabalho. Entretanto, eles são bastante atentos e sensíveis para o que acontece no mundo jornalístico na contemporaneidade, ou seja, de fato a receita publicitária é o fator que mais incide sobre suas atividades. A demanda da receita publicitária escapou do setor da administração da empresa de comunicação para conformar o produto editorial já na bancada do jornalista. Tanto isso é verdade que cada vez mais se torna prática do setor a aproximação entre administração e redação, fato que há alguns anos seria tomado como verdadeira heresia para a prática jornalística.

Como garantir o direito à informação se as práticas e rotinas vivenciadas no trabalho confirmam o pressuposto de que o negócio vai adiante da pluralidade de pontos de vista? Quais são os valores aí implícitos e qual é a ética desse trabalho?

A resposta a essas questões pode ser inferida do que os comunicadores responderam ao serem inquiridos se os cidadãos podem tomar decisões importantes a partir do conteúdo veiculado pelos meios de comunicação. 
Embora a maioria afirme que decisões importantes podem ser tomadas a partir do que os meios veiculam, em ambas as empresas, $45 \%$ dos respondentes afirmam que apenas às vezes se podem tomar decisões importantes a partir dos meios de comunicação. Ou seja, uma parcela relevante dos entrevistados já admite que o fruto de seu próprio trabalho merece sofrer o benefício da dúvida para ser levado em conta.

Portanto, vê-se como os debates de normas e as dramáticas do uso de si acontecem no mundo do trabalho dos comunicadores no que eles têm de mais relevante em seu fazer, isto é, o reconhecimento do valor social do exercício de sua profissão.

Sobre o perfil socioeconômico e cultural dos comunicadores cabe rápido comentário. Eles são jovens, profissionais bem escolarizados, que trabalham em jornadas extensas e em ritmo acelerado. Nos locais de trabalho, passam pelo mesmo tipo de reorganização flexível do processo de produção que outros setores econômicos passaram. Eles são os consumidores privilegiados dos produtos culturais que eles mesmos produzem. Fazem parte de uma camada de consumidores para a qual estão voltadas as principais atenções do mercado da cultura. Como profissionais, a maioria dos entrevistados não tem clara a distinção e os limites entre negócio, produto e direito à informação.

O mercado de trabalho para o comunicador é pequeno e exigente. As empresas requerem um profissional com habilidades em multiplataformas, com destreza no uso da língua e das linguagens para poder produzir enunciados de acordo com os requisitos das diferentes plataformas e dos objetivos de consumo (Figaro, 2008b). Exigem noções de marketing e de administração, visto que se priorizam o consumidor e a segmentação de públicos. Há produtos para todos. Informação como entretenimento é a receita certa mesmo quando os públicos são mais sofisticados. Há um nível de exigência bastante alto de dedicação do profissional para condições de trabalho que se vêm deteriorando.

As relações no trabalho ficaram mais competitivas, fazendo com que os embates de normas coloquem em questão os valores de solidariedade nos coletivos de trabalho. Fato esse que leva a comportamentos, por parte do profissional, nem sempre respaldados em valores éticos. A concorrência entre colegas, a falta de camaradagem, as condições contratuais precárias freelancer, pessoa jurídica e cooperados - deixam o profissional em situação de desvantagem. Jornadas de trabalho extensas, ritmo acelerado de trabalho corroboram para situações que exigem do comunicador maior atenção e provocam tensão que, conforme também aponta Heloani (2008), tem sido causa de estresse e descontentamentos. Mais um fato a demonstrar como a atividade de trabalho conformada por determinadas normas cobra do corpo psicofísico, questionando a saúde e o 'vivível' no trabalho. 


\section{Considerações finais}

A título de síntese, pode-se afirmar que a abordagem ergológica de comunicação e trabalho propicia ressignificar ambos os conceitos tendo-os como atividade humana central na formulação de uma teoria social. A abordagem ergológica permite destacar a dialética do debate de normas e valores no inédito da atividade humana. A análise das situações de trabalho dos comunicadores, na perspectiva ergológica, articulada à ontologia do ser social, possibilita compreender essas situações a partir do sujeito que trabalha, das redes de relações forjadas pela atividade concreta de trabalho e relacionálas aos contextos e às injunções dos diferentes interesses socioeconômicos, inerentes ao sistema capitalista.

No caso dos comunicadores, analisou-se, à luz da abordagem ergológica, um dos principais aspectos que caracterizam o seu fazer profissional - a credibilidade da informação em relação às demandas de receita publicitária -, chegando-se à conclusão de que esse é um dos principais pontos de embate de normas vivenciados por esses profissionais. Ele é fonte de tensão, de estresse e de maior ou menor reconhecimento social de seu trabalho.

Apesar da dificuldade de se conseguir autorização das empresas de comunicação para se observar o trabalho in loco, é de fundamental importância que se realizem pesquisas sobre o mundo do trabalho dos comunicadores. A abordagem ergológica, como conjunto de propostas para a análise das situações de trabalho, pode colaborar em muito para esses estudos.

\section{Notas}

${ }^{1}$ Professora da Escola de Comunicações e Artes da Universidade de São Paulo (ECA/USP) e coordenadora do grupo de pesquisa "Comunicação e trabalho" da ECA/USP/CNPq, São Paulo, Brasil. Doutora em Ciências da Comunicação pela USP, com pós-doutorado na Universidade de Provence, França. <figaro@uol.com.br>

Correspondência: Rua Itacema, n. 366, apto. 61, Itaim Bibi, CEP 04530-051, São Paulo, SP, Brasil.

2 Estudo realizado pelo grupo de pesquisa "Comunicação e trabalho", da ECA/USP/CNPq, com apoio da Fapesp, entre 2005-2008. A parte empírica baseou-se no estudo de perfis de profissionais de comunicação empregados em grandes empresas do setor editorial, publicitário e de televisão. Foi estruturada metodologicamente em duas fases: uma quantitativa e outra qualitativa. Na fase quantitativa fez-se o levantamento do perfil do comunicador, trabalhadores dessas empresas; na fase qualitativa contou-se com o instrumento do roteiro de questões abertas para entrevista em profundidade com uma amostra desses trabalhadores, 
com o objetivo de colher e analisar os depoimentos sobre trajetórias profissionais e mudanças no mundo do trabalho nas empresas de comunicação.

3 Essa reflexão, embora polêmica, precisa ser realizada e desenvolvida. Em nosso caso, ela é um desafio que começamos a enfrentar.

4 A emenda n. 36 mudou a Constituição de 1988, e a lei n. 10610, de maio de 2002, dispõe sobre a participação de até $30 \%$ de capital estrangeiro em empresas brasileiras de comunicação. No entanto, como há perfis diferenciados de negócio (indústria gráfica, agência de notícia, TV a cabo etc.), não se sabe ao certo o total de capital nacional que ainda resta nas empresas do setor.

${ }^{5}$ Mito que pressupõe uma sociedade democrática em que os poderes Executivo, Legislativo e Judiciário funcionem com independência e sob a mira da fiscalização da imprensa, o quarto poder.

6 Originada a partir dos resultados do trabalho da Comissão para a Liberdade de Imprensa, instalada no final da década de 1940 nos EUA.

\section{Referências}

BAKHTIN, Mikhail (Voloshinov). Marxismo e filosofia da linguagem. São Paulo: Hucitec, 1988.

COSTA, Frederico Jorge F.; VASCONCELOS, Susana Jimenez. A natureza ontológica do pensamento de Marx. In: CONFERÊNCIA INTERNACIONAL CARLOS MARX Y LOS DESAFÍOS DEL SIGLO XXI, 5., maio 2008, Cuba. Disponível em: <www.nodo50.org/ cubasigloXXI/congreso08/conf4_ferreiraj. pdf $>$. Acesso em: 15 jan. 2011.

DURAFFOURG, Jacques. O trabalho e o ponto de vista de vista da atividade. In: SCHWARTZ, Yves; DURRIVE, Louis (Orgs.). Trabalho e ergologia: conversas sobre a atividade humana. Rio de Janeiro: EdUFF, 2007. p. 47-82.

FAUSTINO, Paulo. A imprensa em Portugal: transformações e tendências. Lisboa: Media XXI, 2004.

(Org.). Ética e responsabilidade social dos media. Lisboa: Media XXI, 2007.
FIGARO, Roseli. Atividade de comunicação e de trabalho. Trabalho, Educação e Saúde, Rio de Janeiro, v. 6, n. 1, p. 107-145, mar./jun. 2008a.

Comunicação e trabalho: as mudanças no mundo do trabalho nas empresas de comunicação. São Paulo: Fapesp, 2008b. Disponível em: <www.eca.usp.br/ comunicacaoetrabalho/wp/index.php/ pesquisas/2005-2007>. Acesso em: 14 jan. 2011 .

FOLCHER, Viviane; RABARDEL, Pierre. Homens, artefatos, atividades: perspectiva instrumental. In: (Eds.). Collective and individual uses of a cooperative tool in a work setting: problems of design and reuse. International Conference on the Design of Cooperative Systems, 3., May 1998, Cannes. p. 25-28.

HELOANI, Roberto. Mudanças no mundo do trabalho e impactos na qualidade de vida do jornalista. Comunicação apresentada no Congresso Extraordinário da Federação Nacio- 
nal dos Jornalistas, São Paulo, 2008. Disponível em: <www.fenaj.org.br/saude/ apres_roberto_heloani.ppt $>$. Acesso em: 14 jan. 2011.

IBGE (Instituto Brasileiro de Geografia e Estatística). Perfil da economia da cultura, 2003-2005. Rio de Janeiro: IBGE, 2006.

LEONTIEV, Alexis. Le développement du psychisme. 3. ed. Paris: Éditions Sociales, 1976.

MESQUITA, Mário. O quarto equívoco: o poder dos media na sociedade contemporânea. Coimbra: Minerva, 2006.

MORAIS, Ana Sofia. Os meios de comunicação como empresa. In: FAUSTINO, Paulo (Org.). Ética e responsabilidade social dos media. Lisboa: Media XXI, 2007. p. 101-143.

MORIN, Edgar. Cultura de massas no século $X X$ : neurose. 9. ed. 2. reimp. Tradução de Maura Ribeiro Sardinha. Rio de Janeiro: Forense Universitária. 2002.
SCHWARTZ, Yves. Reconnaissance du travail: pour une approche ergologique. Paris: PUF, 1997.

Trabalho e ergologia. In: SCHWARTZ, Yves; DURRIVE, Louis. (Orgs.). Trabalho e ergologia: conversas sobre a atividade humana. Rio de Janeiro: EdUFF, 2007a. p. 25-36.

A linguagem em trabalho. In: SCHWARTZ, Yves; DURRIVE, Louis (Orgs.). Trabalho e ergologia: conversas sobre a atividade humana. Rio de Janeiro: EdUFF, 2007b. p. 133-150.

SCHWARTZ, Yves; DURRIVE, Louis. (Orgs.). Trabalho e ergologia: conversas sobre a atividade humana. Rio de Janeiro: EdUFF, 2007.

UNESCO. Rapport mondial sur la culture. Paris: Unesco, 2000.

Recebido em 17/01/2011

Aprovado em 20/02/2011 